\title{
Habitat, distribution, and abundance of the commercial octopus (Octopus insularis) in a tropical oceanic island, Brazil: Information for management of an artisanal fishery inside a marine protected area
}

\author{
T.S. Leite ${ }^{\mathrm{a}, *}$, M. Haimovici ${ }^{\mathrm{b}}$, J. Mather $^{\mathrm{c}}$, J.E. Lins Oliveira ${ }^{\mathrm{a}}$ \\ a Universidade Federal do Rio Grande do Norte, Lab. Biologia Pesqueira e Mergulho Científico, Dept. Oceanografia e Limnologia, Via Costeira, s/n, \\ Praia de Mãe Luiza, Natal/RN, CEP 59014-100, Brazil

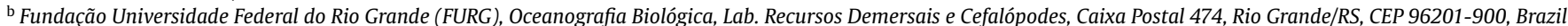 \\ ${ }^{\mathrm{c}}$ University of Lethbridge, 4401 University Drive, Lethbridge, Alberta T1K 3M4, Canada
}

\section{A R T I C L E I N F O}

\section{Article history:}

Received 24 December 2008

Received in revised form 5 April 2009

Accepted 7 April 2009

\section{Keywords:}

Octopus

Marine protected area

Habitat

Abundance

Fishery management

Distribution

\begin{abstract}
A B S T R A C T
The spatial distribution, abundance and habitat of a population of a shallow-water octopus, Octopus insularis, subject to some fishery pressure, was studied in the Fernando de Noronha Archipelago, a marine protected area off northeastern Brazil. Three techniques were used: visual censuses in fixed quadrants and in roving-diver and catch per unit of effort (CPUE) of the commercial fishery. We had two hypotheses, that the species had a nonrandom distribution, related to substrate and body size, and that relative abundance outside the national park would be lower than within, possibly due to fishery pressure. We found a patchy distribution over all, with octopuses almost confined to substrates with a large proportion of hard surfaces. There were seasonal and depth effects on distribution of the very small octopuses found mainly in shallow water (intertidal to $5 \mathrm{~m}$ depth) during the dry season. Abundance was similar inside and outside of the national park, which suggests that the octopus fishery is not a threat to the abundance of $O$. insularis at this present level.
\end{abstract}

(c) 2009 Elsevier B.V. All rights reserved.

\section{Introduction}

The species focus of this study, Octopus insularis (Leite and Haimovici, 2008), is a medium-sized octopus which is the main commercial cephalopod species in shallow waters around tropical oceanic islands and along the northeastern coast of Brazil (Leite et al., 2008c). There are very few data about the biology and ecology of this species yet (Leite, 2007), once that it was not previously distinguished from the Octopus vulgaris complex, being only recently described as a new species (Leite et al., 2008c). In Fernando de Noronha islands, an archipelago $350 \mathrm{~km}$ off the northeastern coast of Brazil (Fig. 1), this species occurs throughout the year in the shallow waters, where it is the focus of an artesian fishery, the only one in an oceanic island from Brazil. The major portion of the archipelago is within the limits of the National Marine Park (without fishery), while the other portion is an Environmental Protection Area where the fishery is allowed. The catches have subsistence, recreational, and commercial aspects, with a rough estimate of the total yearly catch between 3 and 6 tons (Leite et al., 2008a).

\footnotetext{
* Corresponding author. Tel.: +55 843215 4432; fax: +55 8432154432. E-mail addresses: leite_ts@yahoo.com.br (T.S. Leite),docmhm@yahoo.com.br (M. Haimovici), mather@uleth.ca (J. Mather), jorgelins@ufrnet.br (J.E.L. Oliveira).
}

The new species needs to be studied in the same manner as better known ones, especially because it is the subject of a fishery. Information about its variations in distribution and relative abundance in time and space are critical for understanding the ecology of this species (Valiela, 1995) and for fishery management (King, 1995). As cephalopods are soft-bodied refuging animals, the characteristics of the bottom where a benthic octopus lives have been thought to be the main factor influencing its distribution, due to the necessity of protection against predators (Aronson, 1991; Hanlon and Messenger, 1996).

Studies on octopus habitat preference in tropical reefs showed that some characteristics, such as den availability (Aronson, 1986), preference for edge (Anderson, 1997), and preference for backreef over reeftop and forereef (Forsythe and Hanlon, 1997) affected octopus distribution. Moreover, Mather (1982) found a positive correlation between Octopus joubini's clumped distribution and the distribution of molluscan shells in which they hid in a subtropical habitat, and Scheel (2002) observed a positive association for Enteroctopus dofleini density with substrate, kelp cover and shallow waters (up $5 \mathrm{~m}$ depth) in Alaska. Den availability can be also a limiting factor for octopus distribution, as several studies for different species have described home choice and suggest characteristics used in selection of hiding places (Mather, 1982; Altman, 1967; Katsanevakis and Verriopoulos, 
2004b; Hartwick and Thorarinsson, 1978; Forsythe and Hanlon, 1997).

Factors other than habitat may have an important influence on density. Seasonality was very important to E. dofleini migration in British Columbia, Canada (Hartwick et al., 1984) and to Octopus tehuelchus recruitment in Patagonia, Argentina (Iribarne, 1991). Besides the season, depth and temperature were also significant factors in Octopus vulgaris abundance in Greek coastal waters (Katsanevakis and Verriopoulos, 2004a). Biological factors such as predation pressure and reproductive demand were also defined as important determinants to the distribution and density for some octopus species (Aronson, 1986; Leite, 2007; Huffard et al., 2008), while prey availability was not (Mather, 1982; Scheel et al., 2007).

There are several ways to estimate density of a marine animal, and none is satisfactory by itself. Although fishery data-based investigations have been important to assess population densities, this technique requires the sacrifice of a large number of animals and is unacceptable in some environments, such as the marine protected areas, and for endangered species. Direct visual observation has already been used as an important tool to study octopus feeding strategies (Mather, 1991; Hanlon et al., 2008), body patterns (Leite and Mather, 2008), daytime activity (Mather, 1988), and even aspects of the population biology (Oosthuizen and Smale, 2003). Cryptic animals, such as octopuses, pose some difficulties for visual censuses. However, in clear water, such as around tropical oceanic islands, it is possible to observe the distinct hard-bodies prey remains left in front of the dens of cryptic animals, and an adequate sampling design can minimize the obstacles to octopus visual censuses.

In order to understand 0 . insularis' successful dominance in the shallow waters of the tropical oceanic island of the Southwestern Atlantic, information about the population dynamic of this species in the shallow water around Fernando de Noronha Archipelago, as well as the impact of the fishery on this population, were evaluated, and two main hypotheses were tested: (1) 0 . insularis has a nonrandom distribution, related to substrate and body size and (2) $O$. insularis has a lower abundance in areas outside the national park.

\section{Materials and methods}

\subsection{Study area}

O. insularis was studied in Fernando de Noronha Archipelago from 2003 until 2005. The archipelago is composed of a group of 21 northeastern Brazilian oceanic islands $\left(03^{\circ} 51^{\prime} \mathrm{S}\right.$ and $\left.32^{\circ} 25^{\prime} \mathrm{W}\right)$, located at $345 \mathrm{~km}$ NE of Cape San Roque Brazil (Fig. 1). It is an emerged portion of the Mid-Atlantic Ridge with an area of $18 \mathrm{~km}^{2}$.

The shelf around the main island is relatively wide, reaching a diameter of $10 \mathrm{~km}$ at the $100 \mathrm{~m}$ isobaths. The water temperature ranges from 24 to $28^{\circ} \mathrm{C}$ and the salinity is around 36\% (Eston et al., 1986). The south and southeast coasts of the main island are characterized by rocky faces and extensive barriers of calcareous algae and are subjected to strong wave action from April to December. The northeastern shelf is sandy with large stone blocks embedded in the sand. On this side of the islands there is wave action from December to April (Teixeira et al., 2003; MMA/IIBAMA, 2005).

\subsection{Sampling method}

The data were collected at 24 sampling areas around the archipelago in five periods: September/October 2003, January 2004, May/June 2004, July/August 2004, and March/April 2005,

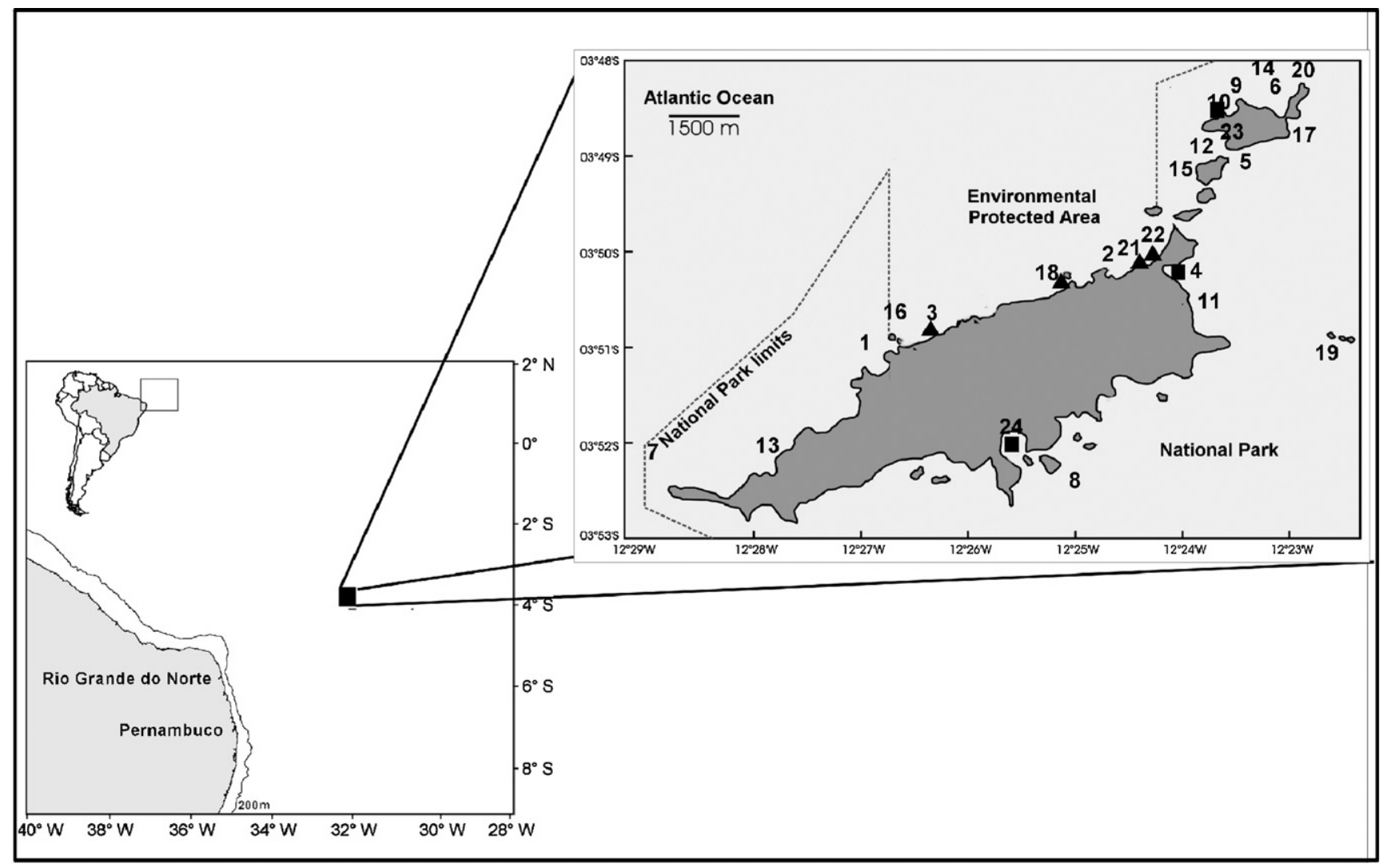

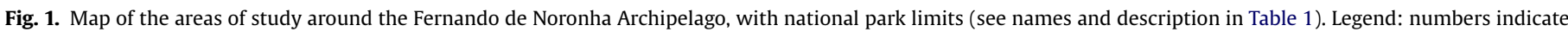
roving-diver areas; squares show fixed-quadrant areas; and triangle show areas of fishing occurrence. 
Table 1

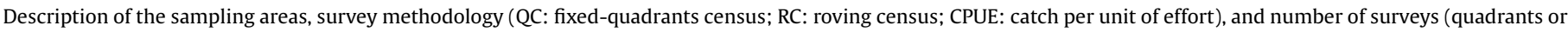
divers) per sample period.

\begin{tabular}{|c|c|c|c|c|c|c|c|c|c|}
\hline \multirow[b]{2}{*}{ No. } & \multirow[b]{2}{*}{$\begin{array}{l}\text { Sampled } \\
\text { areas }\end{array}$} & \multirow[b]{2}{*}{$\begin{array}{l}\text { Survey } \\
\text { method }\end{array}$} & \multirow[b]{2}{*}{$\begin{array}{l}\text { Substrates and } \\
\text { Depth range }(\mathrm{m})\end{array}$} & \multirow[b]{2}{*}{$\begin{array}{l}\text { area } \\
\text { description }\end{array}$} & \multicolumn{5}{|c|}{ Sample per period } \\
\hline & & & & & $\begin{array}{l}\text { September/ } \\
\text { October } 2003\end{array}$ & January 2004 & $\begin{array}{l}\text { May/ } \\
\text { June } 2004\end{array}$ & $\begin{array}{l}\text { July/ } \\
\text { August } 2004\end{array}$ & $\begin{array}{l}\text { March/ } \\
\text { April } 2005\end{array}$ \\
\hline 1 & Baia dos Porcos & $\mathrm{RC}$ & $0-5$ & Sandy beach with bedrocks & & & 1 & 3 & \\
\hline 2 & Biboca & CPUE & $5-10$ & $\begin{array}{l}\text { Rocky and rubble beach with sand } \\
\text { patches }\end{array}$ & & & & 2 & \\
\hline 3 & Boldró & CPUE & $0-5$ & $\begin{array}{l}\text { Sandy beach with a large algacea reef } \\
\text { crest }\end{array}$ & & & & 5 & 2 \\
\hline 4 & $\begin{array}{l}\text { Buraco da } \\
\text { Raquel }\end{array}$ & QC & $0-5$ & $\begin{array}{l}\text { Marine lagoon in the middle of a reef } \\
\text { barrier }\end{array}$ & 1 & 1 & 1 & & 1 \\
\hline 5 & $\begin{array}{l}\text { Buraco das } \\
\text { Cabras }\end{array}$ & $\mathrm{RC}$ & $10-15$ & Channel with rock and bedrock bottom & 3 & & 1 & 3 & 4 \\
\hline 6 & $\begin{array}{l}\text { Buraco do } \\
\text { Inferno }\end{array}$ & $\mathrm{RC}$ & $10-15$ & $\begin{array}{l}\text { Protected bay with rock and sandy } \\
\text { bottom }\end{array}$ & & & 1 & 1 & 3 \\
\hline 7 & $\begin{array}{l}\text { Cabeço da } \\
\text { Sapata }\end{array}$ & $\mathrm{RC}$ & $>20$ & Volcanic elevation with sand bottom & & & 1 & & \\
\hline 8 & $\begin{array}{l}\text { Cabeço } \\
\text { Submarino }\end{array}$ & $\mathrm{RC}$ & $>20$ & Volcanic elevation with sand bottom & & & & & 1 \\
\hline 9 & Cagarras funda & $\mathrm{RC}$ & $>20$ & $\begin{array}{l}\text { Rata island rocky wall with sand } \\
\text { bottom }\end{array}$ & 1 & & 2 & 2 & \\
\hline 10 & Cagarras rasa & QC & $10-15$ & $\begin{array}{l}\text { Protected bay with rock and bedrock } \\
\text { bottom }\end{array}$ & 1 & & 1 & & 1 \\
\hline 11 & Caieiras & $\mathrm{RC}$ & $10-15$ & Bedrock and rocky bottoms & & 1 & 3 & 2 & 2 \\
\hline 12 & Canal da Rata & $\mathrm{RC}$ & $10-15$ & $\begin{array}{l}\text { Channel with small rocks on sandy } \\
\text { bottom }\end{array}$ & 2 & & 2 & 9 & 9 \\
\hline 13 & $\begin{array}{l}\text { Caverna da } \\
\text { Sapata }\end{array}$ & $\mathrm{RC}$ & $15-20$ & $\begin{array}{l}\text { Cave in a large rocky wall, with sandy } \\
\text { bottom }\end{array}$ & & & 4 & 3 & \\
\hline 14 & Cordilheiras & $\mathrm{RC}$ & $15-20$ & Gathering of big rocks on sandy bottom & 2 & & 1 & 3 & 1 \\
\hline 15 & Ilha do Meio & $\mathrm{RC}$ & $10-15$ & $\begin{array}{l}\text { Volcanic island with caves and sandy } \\
\text { bottom }\end{array}$ & 1 & & 1 & 2 & \\
\hline 16 & $\begin{array}{l}\text { Laje dois } \\
\text { irmãos }\end{array}$ & $\mathrm{RC}$ & $15-20$ & Bedrock over a sandy bottom & & & 3 & 2 & \\
\hline 17 & Macaxeira & $\mathrm{RC}$ & $>20$ & Rata island rocky wall & & & & & 1 \\
\hline 18 & Morro de For a & $\mathrm{RC}$ & $0-5$ & $\begin{array}{l}\text { Volcanic cliff, on sandy and rocky } \\
\text { bottom }\end{array}$ & & & & 1 & \\
\hline 19 & Pedras secas & $\mathrm{RC}$ & $10-15$ & $\begin{array}{l}\text { Volcanic cliff with calcarea algae } \\
\text { bottom }\end{array}$ & 1 & & 1 & 5 & 2 \\
\hline 20 & Pontal do Norte & $\mathrm{RC}$ & $>20$ & Volcanic elevation with sandy bottom & 1 & & & 2 & 1 \\
\hline 21 & Porto-left side & CPUE & $0-5$ & Bedrock with sandy patches & & & & 2 & \\
\hline 22 & $\begin{array}{l}\text { Porto-right } \\
\text { side }\end{array}$ & CPUE & $5-10$ & $\begin{array}{l}\text { Rubble and bedrock beach with sand } \\
\text { patches }\end{array}$ & 2 & & & 2 & \\
\hline 23 & Ressurreta & $\mathrm{RC}$ & $5-10$ & $\begin{array}{l}\text { Protected bay, with rocky walls on } \\
\text { sandy bottom }\end{array}$ & 7 & 1 & 4 & 8 & 4 \\
\hline 24 & Sueste & $\mathrm{QC}$ & $0-5$ & $\begin{array}{l}\text { Protected bay with bedrock and sandy } \\
\text { patches }\end{array}$ & 1 & 1 & 1 & & 1 \\
\hline
\end{tabular}

using three underwater techniques: visual censuses in fixed quadrants $(n=3)$ (Krebs, 1989), roving-diver visual census $(n=17)$ (Schmitt and Sulivan, 1996), and catch per unit of effort (CPUE), collected through interviews of the commercial octopus fishery $(n=4)$ (Leite et al., 2008a) (see Table 1).

The sampling areas were chosen based on previous knowledge of octopus habitats. The areas characterized as poor habitats were sampled sufficiently often to establish a relative absence of octopus there $(n=4)$.

\subsection{Visual census for fixed quadrants $(Q C)$}

We surveyed the presence of octopuses in fixed quadrants of $50 \mathrm{~m} \times 50 \mathrm{~m}$ in three areas. Buraco da Rachel and Sueste quadrants were sampled during snorkeling, and the Cagarras Rasas quadrant was sampled during scuba dives (Fig. 1 and Table 1). The quadrants were marked with buoys and subdivided into 25 smaller squares of $10 \mathrm{~m} \times 10 \mathrm{~m}\left(100 \mathrm{~m}^{2}\right)$ using a gyro-compass and a tape measure, and all of the quadrants were sampled visually; all holes and crevices were examined. Dens were identified by both presence of an octopus and fresh prey remains of mollusks and crustaceans. Octopus size was recorded as small (S: under $80 \mathrm{~mm}$ $\mathrm{ML}$ ), medium (M: $80-100 \mathrm{~mm} \mathrm{ML),} \mathrm{or} \mathrm{large} \mathrm{(L:} \mathrm{over} 100 \mathrm{~mm} \mathrm{ML).}$
Maps with detailed description of the substrate, den locations, and distance to the nearest den (m) were drawn for each quadrant.

This fixed-quadrants design was used to test the hypothesis of nonrandom octopus distribution, with density as a function of octopus body size and ecological variables (substrate, depth and season). To test if the octopuses were randomly distributed, the Standardized Morisita index $\left(I_{\mathrm{p}}\right)$ was calculated for each area (Krebs/Win Program 0.9). This index ranges from -1.0 to +1.0 , with $95 \%$ confidence limits at +0.5 and -0.5 (Krebs, 1989). Random patterns give $I_{\mathrm{p}}=0$, clumped patterns give $I_{\mathrm{p}}>0$, and uniform patterns give $I_{\mathrm{p}}<0$. Due to the small number of octopuses sampled, the distribution of all individuals observed during the survey in the $10 \mathrm{~m} \times 10 \mathrm{~m}$ quadrants in each area $(25 \times$ no. months sampled $)$ was considered, regardless of the month.

One-way ANOVA and Tukey $t$-tests were used to evaluate the influence of octopus size on the distance to nearest octopuses (Statistic soft. 6.0). The variation of relative abundance with sample areas and season was tested with a Factorial ANOVA. A $t$-test checked the variation of relative abundance with depth (intertidal $[0-5 \mathrm{~m}]$ versus subtidal $[10-15 \mathrm{~m}]$ regions). A nested design-ANOVA and Tukey $t$-test were used to check the variation of relative abundance throughout the substrates in the sample areas 
(GLM procedure, Statistic soft. 6.0). The relative abundance in different substrates: bedrock without sand ( $\mathrm{H} 0)$; bedrock with sand $(\mathrm{H} 1)$; rock without sand (R0); rock with sand (R1); unconsolidated sand (U1), was calculated by dividing the number of octopuses found in a particular type of substrate by the number of small squares $(10 \mathrm{~m} \times 10 \mathrm{~m})$ with this substrate type. The equation $\log (x+1)$ was used to normalize relative abundance data (Zar, 1999).

\subsection{Roving-diver visual census ( $R C)$}

We performed an adapted "roving-diver" survey method in 16 areas around Fernando de Noronha and Rata Islands, from the subtidal zone (below $5 \mathrm{~m}$ ) to $40 \mathrm{~m}$ depth (Fig. 1). The depth was divided into three categories (5-10 m, 10-15 $\mathrm{m}$ and $<15 \mathrm{~m}$ ). In each census, all octopuses outside or inside the dens were counted, and substrate, den type, and depth were recorded. The depth was recorded by a dive digital computer. The mean relative abundance for each area at each time was calculated as the total number of octopuses counted divided by time, where the amount of time consumed examining each den was estimated as $3 \mathrm{~min}$ and subtracted from the total census time.

The roving census allowed coverage of a larger number of areas than the fixed quadrants, and the relative abundance estimates could be compared with the CPUE in the octopus fishery areas. A regression between the census time and the number of octopuses observed during the census was performed in order to evaluate the efficiency of the roving census methodology to calculate relative abundance data.

This sampling design allowed us to test the hypothesis that physical environmental variables such as location (sampled area, depth, and archipelago side) and temporal variable (season), influence octopus relative abundance in the subtidal region. The variation of octopus relative abundance with depth, side of island, and season was tested by the main effects ANOVA. To decrease bias, areas with less than two octopuses registered throughout the census were not considered. Differences among sampling areas were tested separately by the one-way ANOVA. The relative octopus abundances data were transformed with $\log (x+1)$ to stabilize variances and normalize data (Zar, 1999).

\subsection{Catch per unit of effort (CPUE)}

The relative octopus abundance inside the national park (without fishery) might have been influenced by commercial fishing in areas outside the park. Outside the park, the catch per unit of effort (number of animals caught/hour of search) reported in questionnaires filled out by fishermen was used as an index of the relative abundance (no. octopus/fisherman dive time). The abundance inside the national park was estimated by the RC method, which is a comparable method to the CPUE (see Section 2.4). We compared the mean relative abundance among three areas inside the national park: Baia dos Porcos (0-5 m), Ressurreta (5-10 m), and Buraco do Inferno (10-15 m), and three areas outside the national park: Porto left side $(0-5 \mathrm{~m})$, Boldró $(0-5 \mathrm{~m})$ and Porto right side (2-10 $\mathrm{m}$ ), by the Mann-Whitney $U$-test, both in two sampling times. All compared areas had similar habitats and were surveyed at a similar time of the year (May/July 2004).

\subsection{Distribution of sizes of octopuses versus den type}

The overall distribution of octopus sizes was tested by a distribution-fitting procedure (Statistic soft. 6.0). For the analysis of distribution, octopuses size were divided into four categories: extra small (SS: under $50 \mathrm{~mm} \mathrm{ML),} \mathrm{small} \mathrm{(S:} \mathrm{50-80} \mathrm{mm} \mathrm{ML),} \mathrm{medium} \mathrm{(M:}$ 80-100 mm ML), and large ( $\mathrm{L}:<100)$. Dens were classified into four categories-(1) soft bottom (B): octopus sheltered under a rock rest- ing on top of any soft bottom; (2) horizontal crevice (CH): octopus sheltered in a crack or crevice in a hard substrate, such as outcrop or bedrock; (3) vertical crevice (CV): octopus sheltered in a vertical crack or crevice in a hard substrate, such as a vertical wall; and (4) between rocks $(\mathrm{R})$ : octopus sheltered in a space between two rocks. A Multiway Contingency Analysis was used to analyze whether the occurrence of the den categories was correlated with the four octopus sizes $(4 \times 4$ contingency table) (SPSS 11.5; Zar, 1999). Octopuses found outside the dens were not taken into account. This analysis tests the hypothesis that the frequencies of occurrence in the various categories of one variable are independent of the frequencies in the second variable. Because the variables were categorical, with no intrinsic order, we chose the contingency coefficient as a significance measure. The correlations were deemed significant at $p<0.025$. Then, the main effects of three depth categories $(0-5 \mathrm{~m}$, $5-10 \mathrm{~m}$ and $>10 \mathrm{~m}$ ), substrates (see quadrants methodology), season, and side of the island (north or south) were evaluated as independent predictors of the occurrence of the four octopus size categories described above, using a multinomial logistic regression (SPSS Program 11.5). A multinomial logistic regression is useful to classify subjects based on values of a set of independent nominal variables. This is a generalization of the logistic regression, in which the dependent variable is not restricted to two categories (Zar, 1999). Parameter estimation was performed through an interactive maximum-likelihood algorithm. The correlations were deemed significant at $p<0.025$.

\section{Results}

Overall, 263 Octopus insularis were recorded from the intertidal zone to 40 m deep: 98 during 127 scuba dives (4926 min), 117 during 47 snorkeling dives ( $4555 \mathrm{~min}$ ), and 48 during 8 fisherman dives (854 min).

\subsection{Fixed-quadrants survey}

We found 101 octopuses (54 small, 26 medium, and 21 large) in the fixed quadrants, but only the octopuses found in dens $(n=94)$ were considered for the statistical analyses of distribution and relative abundance. The distribution analysis pointed out an aggregate distribution (binomial negative distribution) (Morisita index $>0$ ). The inter-den distances varied from 0.2 to $25 \mathrm{~m}$ (mean $(M): 7.88 \mathrm{~m}$; standard deviation (S.D.): 5.25). The inter-den distances were significantly higher between medium-sized pairs compared to smaller and larger ones $(F=3.4063, \mathrm{df}=5, p<0.001$; Tukey, $p<0.05)$ (Fig. 2).

Densities varied from 0.12 to 0.88 individual per $100 \mathrm{~m}^{2}$. Relative abundance differed significantly among sampled areas $(F=7.09$, $\mathrm{df}=2, p<0.05$ ), but not between seasons (ANOVA, $p>0.05$ ) or depths ( $t$-test, $p>0.05)$. Sueste $\left(M: 0.55\right.$ ind. $\left./ 100 \mathrm{~m}^{2}\right)$ showed significantly higher relative abundance than Buraco da Rachel ( $M$ : 0.21 ind. $/ 100 \mathrm{~m}^{2}$ ) (Tukey, $p<0.05$ ) (see areas in Fig. 1 and Table 1 ). Abundance also varied significantly with substrate, from 0 to 4.5 ind. $/ 100 \mathrm{~m}^{2}(F=3.28 ; \mathrm{df}=11, p<0.01)$. However, the abundance was only significantly higher in rock with sand $\left(M: 4.5\right.$ ind. $\left./ 100 \mathrm{~m}^{2}\right)$ than in rock without sand ( $M$ : 0.1 ind. $/ 100 \mathrm{~m}^{2}$ ) (Tukey, $p<0.05$ ).

\subsection{Roving-diver visual census}

Ninety-four octopuses ( small $=32$, medium $=38$, large $=22$ ) were found by visual census $(68.2 \mathrm{~h})$. To check the efficiency of the roving census in measuring abundance, the number of octopuses seen and the corresponding search time were plotted (Fig. 3). The mean number of octopuses recorded increased with roving times ( $b=1.3704, r^{2}=0.56, n=28$ ) however, these increases were greater over times until $3 \mathrm{~h}$. The equation for the line of best fit was 


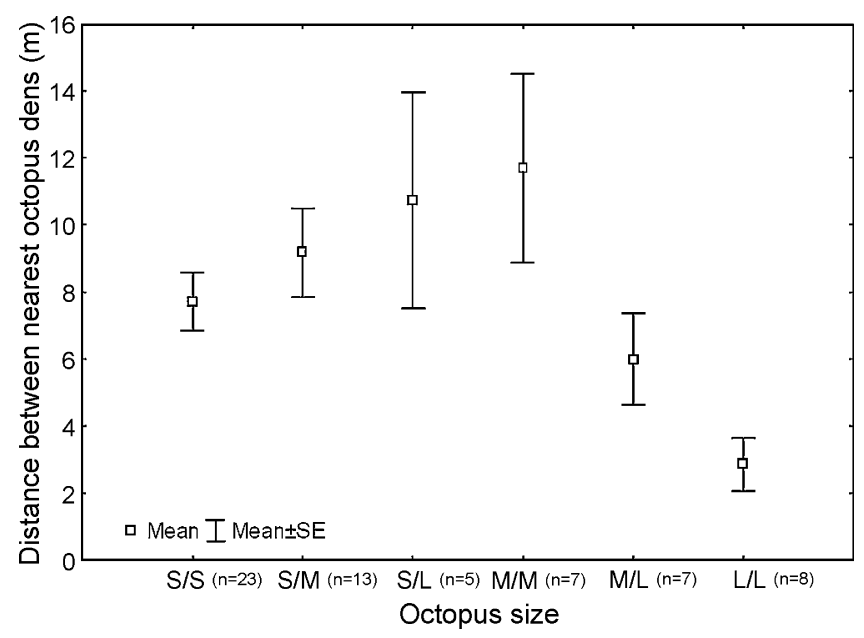

Fig. 2. Mean and standard error (S.E.) line of the minimum distance between the nearest 0 . insularis dens according to the size of the two den occupants ( $n=$ number of observations). Legend: $S / S=$ dens occupied by two small octopuses; $S / M=$ dens occupied by a small and a medium octopus; $\mathrm{S} / \mathrm{L}=$ dens occupied by a small and a large octopus; $\mathrm{M} / \mathrm{M}$ = dens occupied by two medium octopuses; $\mathrm{M} / \mathrm{L}=$ dens occupied by a medium and a large octopus; and $\mathrm{L} / \mathrm{L}=$ dens occupied by two large octopuses.

$y=1.3704 x$. The mean number of records did not increase at the same rate for longer periods.

The mean densities varied from 0 to 3.9 ind./h census. Lower densities were observed in deeper areas $(>20 \mathrm{~m})$, with a maximum of one individual observed in two areas. Also, no octopuses were observed in Caverna da Sapata and Laje dos Dois Irmãos, both at depths below $15 \mathrm{~m}$ (see Table 1). Variations of relative abundance were analyzed for depth, season, island side, and sample areas. Relative abundance did not vary significantly among depth categories, side of island, or season in the subtidal region, from 5 to $20 \mathrm{~m}$ (main effects ANOVA, $p>0.05$ ). Sample areas also did not influence the relative abundance (ANOVA, $p>0.05$ ).

\subsection{Octopus fishery areas survey}

Relative densities did not vary between in-park and outside (fishery areas) ( $U$-test, $p>0.05$ ), although the abundance was predominantly outside (outside: $M$ : 3.70; S.D.: 1.46; park: $M$ : 1.78, S.D.: 0.64). The CPUE varied from 2 ind./h in Boldró in March 2005, to 5 ind./h in Conceição Beach in July 2004.

\subsection{Distribution of sizes of octopuses versus den type}

The overall distribution of octopus sizes showed an approximate normal distribution (distribution normal fitting: chi-square test $=15,586, \mathrm{df}=1, \quad p<0.0001)$, with most of the octopuses

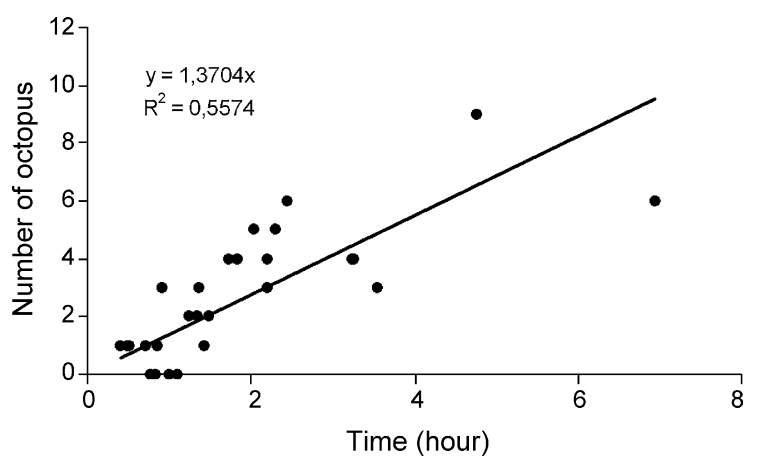

Fig. 3. Regression between time sampled during individual roving census and the number of octopuses found $\left(n=28, r^{2}=0.56\right)$.

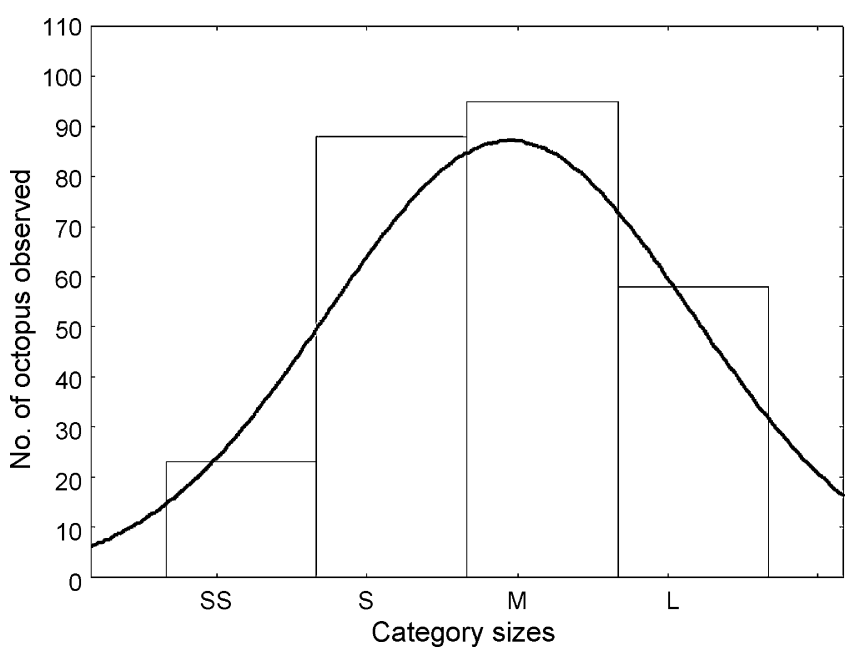

Fig. 4. Total number of octopuses found per size category. (SS = under $50 \mathrm{~mm} \mathrm{ML}$ ), small ( $\mathrm{S}=50-80 \mathrm{~mm} \mathrm{ML})$, medium $(\mathrm{M}=80-100 \mathrm{~mm} \mathrm{ML})$, large $(\mathrm{L}=>100)$.

observed classified as medium $(n=95)$ and a few in the extreme categories such as extra small $(<50 \mathrm{~mm} ; n=22)$ or large $(>130 \mathrm{~mm}$; $n=58$ ) (Fig. 4).

In general, $O$. insularis preferred dens under rock in soft bottoms and dens in horizontal crevices (>86\% of occurrence), while dens in vertical crevices were less attractive. The Multiway Contingency Analysis showed a significant relationship between octopus size and den type (CC $(4 \times 4): 0.288, p<0.025 ; n=224)$. This relationship was clearer among extra-small octopuses, as more than $70 \%$ of this size category occupied dens in horizontal crevices and none in dens between rocks (Fig. 5).

The regression among octopus size categories and environmental variables showed a significant relationship (model: chi-square $=55.88 ; \mathrm{df}=21 ; p<0.025$ ). There were significant effects of season (chi-square $=10.38 ; \mathrm{df}=3 ; p<0.025$ ) and depth (chisquare $=16.015 ; \mathrm{df}=6 ; p<0.025$ ) on octopus size occurrence. Small octopuses occurred more frequently in the rainy season (60\%) and medium-sized ones occurred more frequently in the dry season (57\%), but the difference was not highly significant. The main trend was the common occurrence of the smaller octopuses in the most shallow waters $(0-5 \mathrm{~m})$, while the bigger octopuses showed no significant preference ( $E S=90 \% ; S=53 \%$; and $M=42 \%$ ) (Fig. 6).

\section{Discussion}

Like other octopus species (Mather, 1982; Hartwick et al., 1984; Iribarne, 1991; Aronson, 1986; Katsanevakis and Verriopoulos, 2004a,2006; Scheel, 2002) O. insularis had substrate, season, and interspecific relationships as factors influencing its abundance and

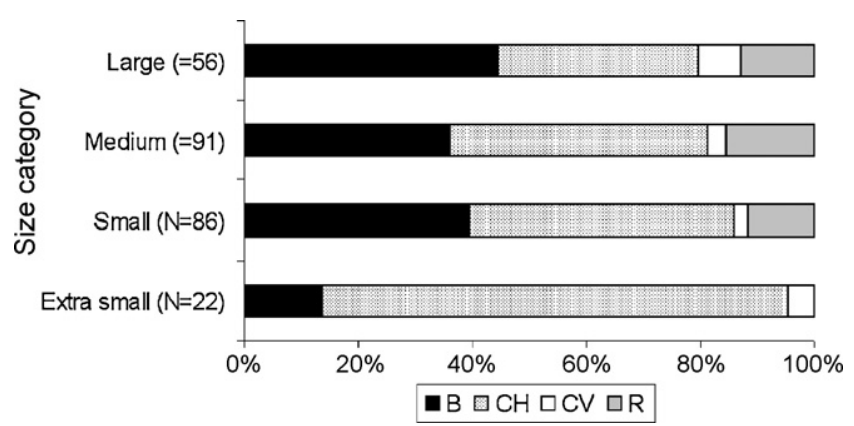

Fig. 5. Occurrence of Octopus insularis size categories across four den types. Legend: $\mathrm{B}=$ dens under a rock resting on top of any soft bottom; $\mathrm{CH}=$ dens in horizontal crevices; $\mathrm{CV}=$ dens in vertical crevices; and $\mathrm{R}=$ dens between two rocks. 


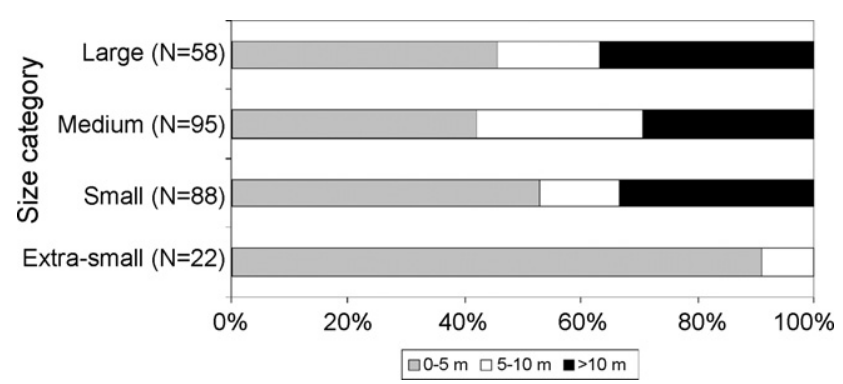

Fig. 6. Occurrence of four Octopus insularis size categories: extra small (SS = under $50 \mathrm{~mm} \mathrm{ML})$, small $(\mathrm{S}=50-80 \mathrm{~mm} \mathrm{ML})$, medium $(\mathrm{M}=80-100 \mathrm{~mm} \mathrm{ML})$, and large $(\mathrm{L}=<100)$ across three depths.

distribution. Despite their restrictions, the three methodologies used at this study pointed to an aggregate distribution of $O$. insularis, influenced not only by environmental variables but also by biological ones like ontogeny and maturity stage. All nondestructive methods used in this study had drawbacks, but used together they complemented each other and produced comparable and consistent results.

Our evidence supports the same clumped distribution found for 0 . vulgaris, which needs hard structures on soft substrates or penetrable areas in hard substrates (Oosthuizen and Smale, 2003; Katsanevakis and Verriopoulos, 2004a).

The den type was also an important factor for O. insularis, especially for the smaller ones. Similar to our results, juveniles of $O$. vulgaris generally occupied holes sunk perpendicular into the substrate, while larger sized specimens excavated dens beneath rocks and ledges. Den modifications by octopuses, such as removing rock and sand and placing items to block the aperture (Mather, 1994), were also performed by 0 . insularis for the two most chosen den types. Dens with fewer possibilities of modification, such as vertical cracks or crevices in a hard substrate, and spaces between two rocks, were less often chosen.

Environmental factors also influenced 0 . insularis density and distribution. The significant relationship of octopus size and depth points to a heterogeneous ontogenetic distribution. The common presence of extra-small octopuses in shallower waters ( $0-5 \mathrm{~m})$ during both seasons suggests that the region functions as a "nursery" for the 0 . insularis post-settlement throughout the year. Any habitat that makes a greater contribution to the recruitment of adults than the average should be considered a nursery habitat (Beck et al., 2001).

Smaller octopuses seem to prefer warmer temperatures found in intertidal regions, perhaps in order to promote faster growth and thus shorten the period during which they are more vulnerable to predation (Katsanevakis and Verriopoulos, 2004a). In cephalopods even small increases in temperature $\left(1-2{ }^{\circ} \mathrm{C}\right)$ during the first 3 months post-hatch could greatly accelerate growth and significantly reduce the time required to reach adult size (Forsythe, 1993). Small- and medium-sized octopuses also showed a higher occurrence in this region, but not notably so, indicating that after the most vulnerable phase, the juveniles probably migrate to deeper waters.

Another possibility is that predation pressure limits the distribution of very small octopuses (Aronson, 1991). Three of the four main predators of $O$. insularis at Fernando de Noronha Archipelago, the nurse shark (Ginglymostoma cirratum), the stingray (Dasyatis americana), and the dog snapper fish (Lutjanus jocu), are not usually seen on the hard substrates in intertidal regions and in depths up $2 \mathrm{~m}$ (personal observation). Only the green moray eel (Gymnothorax funebris) can be found in shallower water, and rarely in intertidal regions (personal observation), which probably indicates less predation pressure on the octopuses at this depth.
A third influence for the juveniles' aggregation in shallower waters is food. Leite (2007) found the number of the preferred prey items per den was larger in depths up to $10 \mathrm{~m}$, indicating that availability of food may also influence the bathymetric distribution for this species.

As observed in other octopus species from tropical regions (Aronson, 1986), the $O$. insularis abundance varied according to physical characteristics of the habitat, such as substrate and depth, but did not vary seasonally, which was observed for 0 . vulgaris from a subtropical region and for E. dofelini from a temperate region (Hartwick et al., 1984; Oosthuizen and Smale, 2003; Katsanevakis and Verriopoulos, 2004a). Its abundance in fixed quadrants (0.12-0.88 ind./100 $\left.\mathrm{m}^{2}\right)$ was similar to Octopus briareus from a tropical insular region $\left(M: 0.79 / 100 \mathrm{~m}^{2} \pm 0.36\right.$; Aronson, 1986).

The high octopus abundance under $15 \mathrm{~m}$ of depth without significant differences throughout the year could be explained by a constant temperature and salinity in the shallow water of this tropical region, without the influence of a shallow thermocline, which is located between 70 and $160 \mathrm{~m}$ in Fernando de Noronha Archipelago (Travassos et al., 1999).

The reproductive behavior related to sex and maturity was another relevant factor observed in this study. The minimum and mean distances between octopus dens $(0.2 \mathrm{~m}$ and $7.88 \mathrm{~m}$, respectively) were much smaller than that observed for E. dofleini $(11 \mathrm{~m}$; Scheel, 2002) and even for the small O. joubini (more than $90 \%$ of octopuses were more than $1 \mathrm{~m}$ apart; Mather, 1982). Leite et al. (in press) found 0 . insularis clumps usually composed of one mature female and up to four mature males around her, suggesting that not only body size but also reproductive maturity could be influenced by these aggregations. Recently, Huffard et al. (2008) observed a similar reproductive association for Abdopus aculeatus from Indonesia, with the mating system incorporating sneaker mating, mate guarding, frequent copulations, and male-male competition for mates.

\subsection{Fishery}

The highest CPUE in areas outside the national park, when compared with abundance in similar areas inside the national park, suggest that fishery areas are very favorable for octopus occurrence. Although studies have pointed out that exploited species generally attain a greater relative abundance inside protected areas (Kenough et al., 1993; Salm et al., 2000), the present results did not show a negative effect of the local fishery on octopus relative abundance outside the marine protected area, yet. The contrast could be explained if octopuses move from national park areas to open areas with suitable habitats available (particularly with dens) (Hartwick et al., 1988; Voight and Greahan, 2000).

Oosthuizen and Smale (2003) suggest that the combined exploitation of inter- and subtidal areas could be detrimental to the octopus stock, as the overexploitation of one area will impact on the other. These two areas should be managed as one, to ensure the sustainable use of octopus resources.

\section{Conclusions and relevance for management}

This kind of study is always necessary when a marine species is exploited, especially inside conservation areas. We could see how numerous and complicated are the influences on octopus populations. Some features of $O$. insularis distribution should be taken into account for management plans. For example, the concentration of extra-small octopuses in shallower water and the apparent lack of their occurrence in deeper water suggest that the shallow areas should be protected to increase the chances for these juveniles 
to reach adulthood. This aspect was proposed in the management plan (Leite et al., 2008b). Furthermore, due to the $O$. insularis aggregated distribution in a few preferred substrates in shallow water, the occurrence of fisheries in some of these preferred areas could increase the impact on the octopus population.

For now, fishing does not appear to pose a serious risk to the octopus population around the Fernando de Noronha islands, as it is restricted to a few dozen part-time fishermen who fish in a small fraction of the total habitat available for the octopus and catch $<7$ metric tons per year (Leite et al., 2008a). Nevertheless, further studies on the distribution of the preferential habitats, in particular where and when mating and brooding take place, are necessary to contribute to an effective management.

\section{Acknowledgments}

We thank the Administration of Fernando de Noronha and the Ministers of Environment (MMA/IBAMA) for their logistic support; the volunteers of UFRN and FURG who cooperated with the field samples; and the fishermen who provided information about the octopus fishery. This study was supported by the Foundation Boticário for Environmental Protection, the Graduate School in Biological Oceanography at the Fundação Universidade Federal de Rio Grande (FURG), and grants by the Brazilian Research Council (CNPq) (T.L. and M.H.).

\section{References}

Altman, J.S., 1967. The behavior of Octopus vulgaris Lam. In its natural habitat: a pilot study. Report of the Underwater Association of Malta.1966-67, 77-83.

Anderson, T., 1997. Habitat selection and shelter use by Octopus tetricus. Mar. Ecol. Prog. Ser. 150, 149-155.

Aronson, R.B., 1986. Life history and den ecology of Octopus briareus Robson in a marine lake. J. Exp. Mar. Biol. Ecol. 95, 37-56.

Aronson, R.B., 1991. Ecology, paleobiology and evolution constraint in the octopus. Bull. Mar. Sci. 49, 245-255.

Beck, M.W., Heck Jr., K.L., Able, K.W., Childers, D.L., Eggleston, D.B., Gillanders, B.M., Halpern, B., Hays, C.G., Hoshino, K., Minell, T.J., Orth, R.J., Sheridan, P.F., Weinstein, M.P., 2001. The identification, conservation, and management of estuarine and marine nurseries for fish and invertebrates. Bio. Sci. Aug., 633-641.

Eston, V.R., Migotto, A.E., Oliveira Filho, E.C., Rodrigues, A.S., Freitas, J.C., 1986. Vertical distribution of benthic marine organisms on rocky coasts of the Fernando de Noronha Archipelago (Brazil). Bol. Inst. Oceanogr. Sao Paulo 34, 37-53.

Forsythe, J.W., 1993. A working hypothesis of how seasonal temperature change may impact the field growth of young cephalopods. In: Okutami, T., O’Dor, R.K., Kubodera, T. (Eds.), Recent Advances in Fisheries Biology. Tokay University Press, Tokyo, pp. 133-143.

Forsythe, J.W., Hanlon, R.T., 1997. Foraging and associated behaviour by Octopus cyanea, 1849 on a coral atoll, French Polynesia. J. Exp. Mar. Biol. Ecol. 209, 15-31.

Hanlon, R.T., Messenger, J.B., 1996. Cephalopod Behaviour. University Press, Cambridge, United Kindgom.

Hanlon, R.T., Conroy, L.N., Forsythe, J.W., 2008. Mimicry and foraging behaviour of two tropical sand-flat octopus species off North Sulawesi, Indonesia. Biol. J. Linn. Soc. 93, 23-38.

Hartwick, E.B., Thorarinsson, G., 1978. Den associates of the giant pacific octopus, Octopus dofleini (Wülker). Ophelia 17, 163-166.

Hartwick, E.B., Ambrose, R.F., Robinson, M.C., 1984. Dynamics of shallow-water population of Octopus dofleini. Mar. Biol. 82, 65-72.

Hartwick, E.B., Robinson, S.M.C., Ambrose, R.F., Trotter, D., Walsh, M., 1988. Inshore-offshore comparison of Octopus dofleini with special reference to abundance, growth and physical condition during winter. Malacologia 29 (1), 57-68.
Huffard, C.L., Caldwell, R.L., Boneka, F., 2008. Mating behavior of Abdopus aculeatus (d'Orbigny 1834) (Cephalopoda: Octopodidae) in the wild. Mar. Biol. 154, 353-362.

Iribarne, O.O., 1991. Life history and distribution of the small south-western Atlantic octopus, Octopus tehuelchus. J. Zool. Lond. 223, 549-565.

Katsanevakis, S., Verriopoulos, G., 2004a. Relative abundance of Octopus vulgaris on soft sediment. Sci. Mar. 68 (4), 553-560.

Katsanevakis, S., Verriopoulos, G., 2004b. Den ecology of Octopus vulgaris Cuvier 1797, on soft sediment: availability and types of shelter. Sci. Mar. 68 (1), 147-157.

Katsanevakis, S., Verriopoulos, G., 2006. Seasonal population dynamics of Octopus vulgaris in the eastern Mediterranean. J. Mar. Sci. 63, 151-160.

Kenough, M.J., Quinn, G.P., King, A., 1993. Correlations between human collection and intertidal mollusk populations on rocky shores. Conservation Biology 7, 378-390.

King, M., 1995. Fishery Biology Assessment and Management. Fishing News Books, Oxford, United Kindgom.

Krebs, C.J., 1989. Ecological Methodology. Benjamin Cummings, New York.

Leite, T.S., 2007. Taxonomia, distribuição, ecologia alimentar, pesca e opções de manejo de uma nova espécie de polvo (Octopus insularis: Cephalopoda), no Arquipélago de Fernando de Noronha, Brasil. Doctorate Thesis, Fundação Universidade Federal de Rio Grande, Rio Grande, RS.

Leite, T.S., Haimovici, M., Lins Oliveira, J.E., 2008a. A pesca de polvos no Arquipélago de Fernando de Noronha, Brasil. Bol. Inst. Pesca São Paulo 34 (2), 271-280.

Leite, T.S., Haimovici, M., Lins Oliveira, J.E., 2008b. Uma proposta de manejo para a pesca do polvo Octopus insularis Leite and Haimovici, 2008 (Mollusca: Cephalopoda) no Arquipélago de Fernando de Noronha. Brasil. Arq. Ciên. Mar. 41 (1), 81-89.

Leite, T.S., Haimovici, M., Molina, W., Warnke, K., 2008c. Morphological and genetic description of Octopus insularis new species (Cephalopoda: Octopodidae), a cryptic species in the Octopus vulgaris complex from the tropical Southwestern Atlantic. J. Molluscan Stud. 74, 63-74.

Leite, T.S., Mather, J., 2008. A new approach to octopuses' body pattern analysis: a framework for taxonomy and behavioral studies. Am. Malac. Bull. 24, 31-41.

Leite, T.S., Andrade, L.C.A., Haimovici, M., Aguiar, R.S., Lins-Oliveira, J.L., in press. Lulas e polvos do Arquipélago de São Pedro e São Paulo. In: O Arquipélago de São Pedro e São Paulo: 10 anos de Estação Científica. Ed. SECIRM, Brasília.

Mather, J.A., 1982. Factors affecting the spatial distribution of natural populations of Octopus joubini Robson. Anim. Behav. 30, 1166-1170.

Mather, J.A., 1988. Daytime activity of juvenile Octopus vulgaris in Bermuda. Malacologia 29, 69-76.

Mather, J.A., 1991. Foraging, feeding and prey remains in midden of juveniles Octopus vulgaris (Mollusca: Cephalopoda). J. Zool. Lond. 224, 27-39.

Mather, J.A., 1994. 'Home' choice and modification by juvenile Octopus vulgaris (Mollusca: Cephalopoda): specialized intelligence and tool use. J. Zool. Lond. 233, 359-368.

MMA/IIBAMA, 2005. Plano de Manejo. APA-Fernando de Noronha - Rocas - São Pedro e São Paulo. Encartes, 1, 2 e 3. Ed. MMA, Brasília.

Oosthuizen, A., Smale, M.J., 2003. Population biology of Octopus vulgaris on the temperate south-eastern of South Africa. J. Mar. Biol. Assoc. U. K. 85, 535-541.

Salm, R., Clarck, J., Siirila, E., 2000. Marine and Coastal Protected Areas: A Guide for Planners and Managers. IUCN, Washington, DC.

Scheel, D., 2002. Characteristics of habitats used by Enteroctopus dofleini in Prince Willian Sound and Cook Inlet. Alaska. Mar. Ecol. 23 (3), 185-206.

Scheel, D., Lauster, A., Vincent, T.L.S., Theile, R., 2007. Habitat ecology of Enteroctopus dofleini from middens and live prey surveys in Prince William Sound, Alaska. In: Landman, N.H., Davis, R.A., Mapes, R.H. (Eds.), Cephalopods Present and Past: New Insights and Fresh Perspectives. Springer, Netherlands, pp. 434-458.

Schmitt, E.F., Sulivan, E.F., 1996. Analysis of a volunteer method for collecting fish presence and relative abundance data in the Florida Keys. Bull. Mar. Sci. 59 (2), 404-416.

Teixeira, W. Cordani, U.G., Menor, E.A. 2003. Caminhos do Tempo Geológico. In: Linsker, R. (Ed.), Arquipélago de Fernando de Noronha o Paraíso do Vulcão. Terra Virgem Editora, São Paulo.

Travassos, P., Hazin, F.H.V., Zagaglia, J.R., Advíncula, R., Schober, J., 1999. Thermohaline structure around seamounts and islands off North-Eastern Brazil. Arch. Fish. Mar. Res. 47, 211-222.

Valiela, I., 1995. Marine Ecological Process. Springer, New York.

Voight, J.R., Greahan, A.J., 2000. Egg brooding by deep-sea octopuses in the North Pacific Ocean. Biol. Bull. 198, 94-100.

Zar, J.H., 1999. Biostatistical Analysis. Prentice-Hall, NJ. 